\title{
$\nabla$ Structural Characterization of Gold Based Ayurvedic Medicine
}

\section{IJCRR}

Section: Healthcare

ISI Impact Factor

(2019-20): 1.628

IC Value (2019): 90.81

$\operatorname{SJIF}(2020)=7.893$

(c) (i) (8)

Copyright@IJCRR

\section{Anushka Tyagi' ${ }^{1}$, Nayan Mishra², Aziz Mohammad Khan ${ }^{3}$}

'Research Scholar, Department of Food and Biotechnology, Jayoti Vidyapeeth Women's University, Jaipur, India; 'Assistant Professor, Department of Education, Jayoti Vidyapeeth Women's University, ]aipur, India; ${ }^{3}$ Assistant Professor, Department of Food and Biotechnology, Jayoti Vidyapeeth Women's University, Jaipur, India.

\section{ABSTRACT}

Introduction: Ayurvedic herbs-mineral medicines are being used as therapeutic drugs since the Vedic era. These medicines are prepared from many sources like minerals, plants and animals through various unique methods.

Objectives: This research aims to synthesize the Gold bhasma (Swarna) by traditional Indian Ayurvedic method and to characterize the Gold nanoparticles by Scanning electron microscopy (SEM), X-ray diffraction (XRD), Photoluminescence spectroscopy and optical absorption.

Methodology: Synthesis of the Gold bhasma was carried out using the unique methods mentioned in Rasashastra like Shodhana (purification), Marana (calcination), Jarana (polling). Characterization of prepared gold nanoparticles was accomplished through X-ray diffraction (XRD), Scanning electron microscopy (SEM), optical absorption and photoluminescence spectroscopy

Result: Swarna bhasma or nanometer-sized gold compound with diameters in the range of 1-20 nm have generated a great deal of interest due to fundamental and technological applications in the drug discovery area.

Conclusion: From this present research work, it can be concluded that prepared Gold Bhasma is an important medicine and has been characterized using scientific characterization methods.

Key Words: Swarna bhasma, gold nanoparticles, X-Ray Diffraction, Scanning Electron, Microscopy, Optical studies

\section{INTRODUCTION}

Ayurveda means the science of the human's internal \& external health. It incorporates the total sweep of biological sciences and pursues the quest for understanding life in all its aftermath. Ayurveda has advised the use of metals $(\mathrm{Cu}, \mathrm{Ag}$, $\mathrm{Au}$ etc) therapeutically in classical texts of Charak Samhita as old as 1500 BC. In Ayurveda, mainly seven metals are used therapeutically. These metals are iron, tin, gold, copper, silver, lead, zinc. ${ }^{1}$ These metals are passed through many purification processes and finally changed into medicinal drug form, called Bhasma. Nanotechnology is considered to be the emerging technology for the current century in the medical field. The basics of nanotechnology lie in the fact that the properties of materials change dramatically when their size is below 50 nanometers. ${ }^{2}$

Ayurvedic bhasmas are ancient nanomedicines. ${ }^{3}$ Importance of Ayurvedic medicine is due to the presence of some bio- active compounds which make them promising medicinal agents for the treatment of all diseases. ${ }^{4,5}$ Ayurvedic bhasmas or metal oxide nanoparticles are believed to be more efficacious than any other healing system because these small particles being insoluble can enter into the bloodstream and are more biocompatible as compared to any chemically or biologically generated nanomaterials. The Bhasmas or metal oxide nanoparticles are combined with herbs which help in the assimilation and delivery of the ingredient drugs into human body. ${ }^{6}$

\section{MATERIALS AND METHODS}

The metal oxide and mineral preparation called bhasma, is also extensively used in Indian traditional ayurvedic medicines. Rasashastra may be defined as a fork of Ayurveda which deals with the various pharmaceutical processes of Shodhana (purification), Marana (calcination), Murchana

\section{Corresponding Author:}

Aziz Mohammad Khan, Assistant Professor, Department of Food and Biotechnology, Jayoti Vidyapeeth Women's University, Jaipur, India. Email: khanazizmohammad@gmail.com

ISSN: 2231-2196 (Print) ISSN: 0975-5241 (Online)

Received: $28.01 .2021 \quad$ Revised: 08.02 .2021

Accepted: 02.04 .2021

Published: 10.08 .2021 
(the procedure by which substances especially mercury is transformed for therapeutic application), Jarana (polling) and other detail description of metals, minerals, herbal drugs and animal products used therapeutically in practice of Ayurveda. The metal gold are heated and dipped in sesam oil when they are red hot, and the process is continued seven times separately. The soft leaves of gold are processed in the same manner with buttermilk, cow's urine, and the extraction of kulatha, kanji and radish. Finally, the leaves are dried by heat. The process of triturating and drying in sunlight is repeated 7-14 times using fresh aliquots of latex and the final product is obtained. An aliquot of the above product is poured into liquefied metallic gold in a closed earthen pot and the mixture is heated above $\sim 850^{\circ} \mathrm{C}$. The content is gently stirred and the heating is continued until the mass becomes disintegrated and a homogenous red-brown powder is formed. ${ }^{7}$

\section{Experimental Techniques}

Bhasmas nanoparticles can only be detected through imaging methods like Electron Microscopy (EM), Scanning Electron Microscopy (SEM), Grazing angle X-Ray diffraction and Rietveld analysis (GXRD). X-ray diffraction analysis was recorded in the grazing angle mode of XRD 6000 SHIMADZU powder diffractometer, using $\mathrm{CuK} \alpha$ line. Beam divergence was restricted with the help of a $0.15 \mathrm{~mm}$ slit on the source site. Drive axis was $2 \theta$ for scan range $20^{\circ}-70^{\circ}$ covered in $2^{\%}$ minute with a step size of $0.02^{0}$ for nanocrystalline swarna bhasma (Au nanoparticle). However, for accurate measurement of peaks and position, X-Ray diffraction data were subsequently recorded using a scan rate of $0.5 \%$ minute. The instrument propagation error in the d-value was $\pm 0.002 \AA .{ }^{8}$

\section{RESULTS AND DISCUSSION}

The crystalline phase identification of the synthesized Swarna bhasma (Gold) nanoparticles was analyzed employing Xray diffraction. The X-ray diffraction patterns of synthesized Swarna bhasma revealed that Au nanocrystals corresponded to the crystalline gold face-centred cubic (FCC) phase. The diffraction peaks obtained at $2 \theta=38.40^{\circ}, 44.26^{\circ}$ and $64.55^{\circ}$ are identical with those reported for standard gold metal (JCPDS, USA). Similarly, the diffraction pattern of Swarna bhasma revealed the existence of peaks (111), (200) and (220) which matched with the standard JCPDS data-04784. ${ }^{9}$

The effect of reduction of the metallic gold particle size was manifested as broadening of the line width and systematic weakening of the intensities of reflexes. The X-ray diffraction peak positions, corresponding interplanar spacing, peak intensities, FWHM, lattice parameter and mean particle size for Swarna bhasma (Au nanoparticles) sample have been summarized in Table 1 and Fig 1.

Table 1: Summary of XRD peak positions, corresponding interplanar spacing, peak intensities, FWHM, miller indices, lattice parameter and particle size for Swarna bhasma (Au nanoparticles) sample.

\begin{tabular}{|c|c|c|c|c|c|c|c|c|}
\hline $\begin{array}{l}\text { S. } \\
\text { No. }\end{array}$ & $\begin{array}{l}\text { Sample } \\
\text { Name }\end{array}$ & $\begin{array}{c}2 \theta \\
(\mathrm{deg} .)\end{array}$ & $\begin{array}{c}\text { Observed } \\
\text { d-values ( } \AA \text { ) }\end{array}$ & \multicolumn{2}{|c|}{ Intensity } & $\begin{array}{l}\text { FWHM } \\
\text { (deg.) }\end{array}$ & $\begin{array}{l}\text { Lattice Paramete } \\
\text { r }(\AA)\end{array}$ & $\begin{array}{c}\text { Particle } \\
\text { Size } \\
(\AA)\end{array}$ \\
\hline \multirow{3}{*}{1} & \multirow{3}{*}{$\begin{array}{l}\text { Swarna } \\
\text { Bhasma }\end{array}$} & $39 \cdot 38$ & 2.41 & 100 & 100 & 0.72 & \multirow{3}{*}{4.221} & \multirow{3}{*}{180} \\
\hline & & 44.97 & 2.05 & 25 & 46 & 0.91 & & \\
\hline & & 65.67 & 1.48 & 30 & 32 & 0.86 & & \\
\hline
\end{tabular}

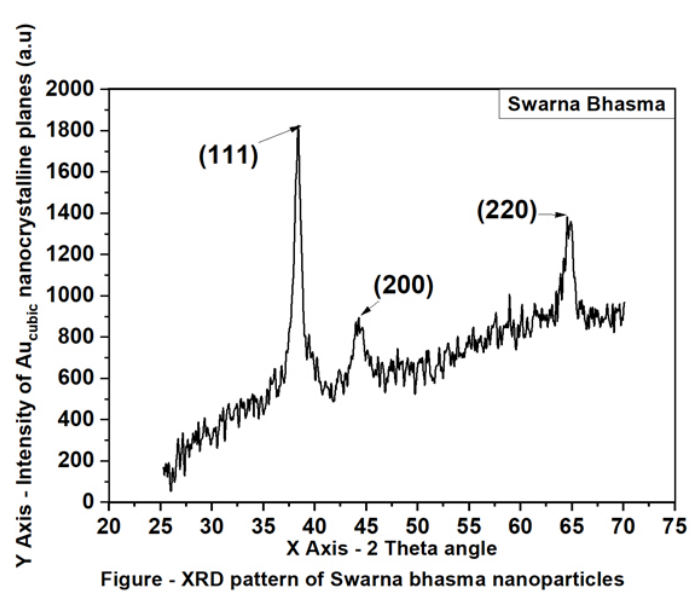

Figure 1: The XRD pattern of Swarna bhasma nanoparticles powder.
The lattice parameter 'a' for all the samples were calculated using the following expression

$$
\mathrm{d}=\frac{a}{\sqrt{h^{2}+k^{2}+l^{2}}}
$$

where (hkl) is miller indices and ' $\mathrm{d}$ ' is more interplane spacing.

The standard value of the lattice parameter for gold is 4.080 $\AA$. It is clear from table 3 that the average value of the lattice parameter for copper nanoparticles is close to the corresponding standard value. ${ }^{10}$

The mean particle size (d) of the Swarna bhasma sample was estimated from the X-ray pattern by using (111) peak according to the Scherrer equation. 


$$
\mathrm{d}=\frac{0.9 \lambda}{B \cos \theta}
$$

Where $\mathrm{B}=\sqrt{{B_{m}}^{2}-B_{S}{ }^{2}}$ is relative broadening (FWHM).

$\lambda$ is the wavelength of $\mathrm{CuK} \alpha(1.5402 \mathrm{~nm}), 2 \theta$ diffraction angle, $\mathrm{B}_{\mathrm{m}}$ is measured broadening and $\mathrm{B}_{\mathrm{S}}$ is the standard broadening determined for standard silicon sample.

The texture coefficient $\mathrm{T}_{\mathrm{c}}(\mathrm{hkl})$ is the preferred orientation indicator for (hkl) plane and is given by the following relationship.

$$
T_{c}(h k l)=\frac{I(h k l) / I_{0}(h k l)}{\frac{1}{N} \sum\left(I(h k l) / I_{0}(h k l)\right)}
$$

Where $I(h k l)$ is measured intensity, $I_{0}(h k l)$ is standard intensity and $\mathrm{N}$ is the no. of reflections. Table 2 compares the calculated texture coefficient for all the observed miller planes in our Swarna Bhasma X-ray diffraction results. It is clear from Table 1 that the value of texture coefficient for (111) lattice plane is greater than unity for all Swarna bhasma samples indicating the tendency of (111) preferred orientation in nanoparticles.

We have also investigated the effects of Shodhana, Marana and Bhawna processes on the surface morphology of crystalline gold using scanning electron microscopy. Figure 2 represents the SEM micrograph of Swarna bhasma. It is clear from blue circles in the figure that the sample of crystalline gold after bhasmikaran process are seen to form spherical type clusters in approximately $200 \mathrm{~nm}$ size. ${ }^{11,12}$

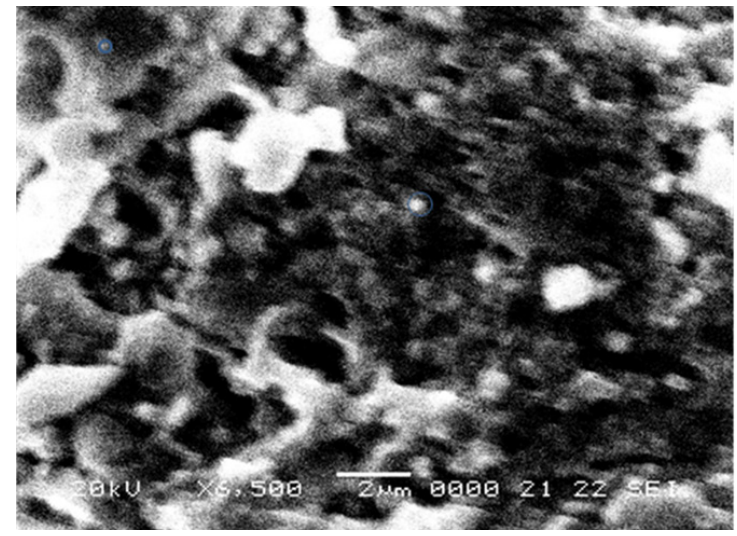

Figure 2: SEM image of Swarna Bhasma nanoparticles powder.

The surface Plasmon resonance of Swarna Bhasma particles is blue-shifted with the reduction in particle size according to Mie theory. The specific optical properties of Swarna Bhasma or gold are due to the valence electron of $5 \mathrm{~d}$ and conduction e- of 6sp orbital's. The outermost orbital d and $\mathrm{s}$ electrons of the constituent atoms must be treated together leading to six energy bands. The five energy bands are fairly flat, lying a very few eV below Fermi level and are usually denoted as d energy bands and the sixth one which is almost free-electron like is known as the conduction band Figure 3. ${ }^{13}$ The nanostructure of Ayurvedic medicine can be used to study the importance of Ayurvedic medicine concerning traditional literature. ${ }^{14,15}$

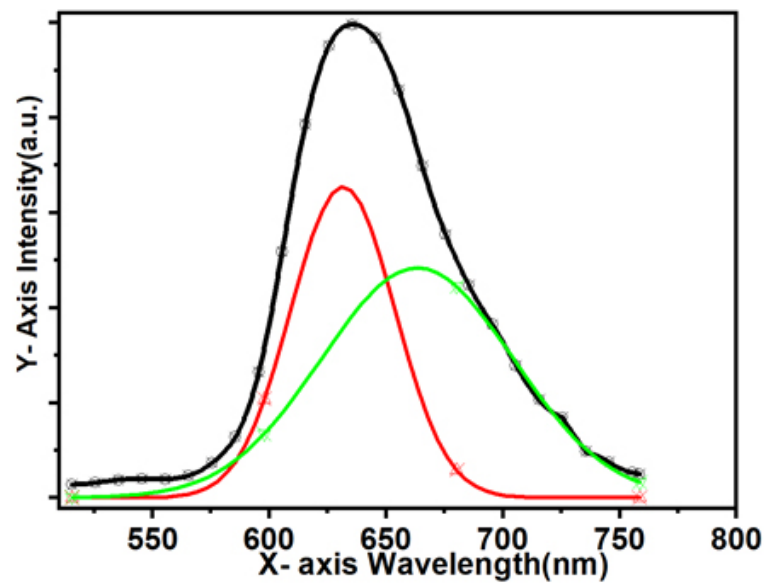

Figure 3: Photoluminescence spectra of Swarna Bhasma Nanoparticles.

\section{CONCLUSION}

We have synthesized Swarna bhasma (Gold) nanoparticles using the Ayurvedic (traditional Indian medicinal method practice) and studied the crystallographic and morphological characterization using X-ray diffraction(XRD) Scanning electron microscope (SEM) and Photoluminescence (PL) techniques. All the analyses confirmed the formation of Swarn Bhasam (Gold) particles in the nanometer regime. The optical absorption showed the intense peak of Swarna bhasma (Gold) nanocrystals at $520 \mathrm{~nm}$ with signs of surface plasmon states near. As prepared Swarna bhasma (Gold) nanoparticles thin film gave rise to another interesting feature with higher intra-band transition were predicted around 490 $\mathrm{nm}$. The XRD, SEM and PL analysis further confirmed the size of nanoparticles is around $\sim 8 \mathrm{~nm}$. Swarn bhasma nanoparticles are showing emission spectra near $600 \mathrm{~nm}$. The nanostructure medicine is a newly used word but in Indian traditional medicine or Ayurvedic therapy in the form of Bhasma, the nanostructures of herbal and minerals are being used as bioavailable and effective medicines.

\section{ACKNOWLEDGEMENT}

The authors are thankful to Jayoti Vidyapeeth Women's University, Jaipur. The authors gratefully acknowledge this 
research to Jayoti Vidyapeeth Women's University, Jaipur. UGC-DAE CSR, Indore for providing facilities for XRD and SEM experiments

\section{Conflicts of interest}

The authors express No conflicts of interest

\section{Source of funding}

No funding sources

\section{REFERENCES}

1. Yeh YC, Creran B, Rotello VM. Gold nanoparticles: preparation, properties, and applications in bionanotechnology. Nanoscale. 2012;4(6):1871-80.

2. Dance A. Medical histories. Nature. 2016 Sep;537(7619):S52-3.

3. Singh RK, Kumar S, Aman AK, Karim SM, Kumar S, Kar M. Study on physical properties of Ayurvedic nanocrystalline Tamra Bhasma by employing modern scientific tools. J Ayurv Integ Med. 2019 Apr 1;10(2):88-93.

4. Khan AM, Bhadauria S, Yadav R. Phytochemical Screening and Antioxidant activity of extract of different parts of Adhatoda vasica. Res J Pharm Techn. 2019 Dec 1;12(12):5699-705

5. Khan AM, Bhadauria S. Isolation of some potential phytocompounds from Adhatoda vasica through Gas Chromatography-Mass Spectroscopy analysis. Asian J Pharm Clin Res. 2017;10(12):328-32.

6. Mukherjee PK, Harwansh RK, Bahadur S, Banerjee S, Kar A, Chanda J et al. Development of Ayurveda-tradition to trend. J Ethnopharm. 2017; 2,197:10-24

7. Chaudhary A. Ayurvedic Bhasma: nanomedicine of ancient India-its global contemporary perspective. J Biomed Nanotech. 2011 Jan 1;7(1):68-9.
8. Cullity BD. Elements of X-ray Diffraction. Addison-Wesley Publishing; 1956.

9. Ren X, Song Y, Liu A, Zhang J, Yang P, Zhang J, An M. Experimental and theoretical studies of DMH as a complexing agent for a cyanide-free gold electroplating electrolyte. RSC Adv. 2015;5(80):64997-5004.

10. Daniel NJ, Thangaraj N, Suresh DM, John NJ. Electrical Measurements on Cadmium Selenite Nano Composites. Int J Cur Res Rev.2017; 26;9(24):1.

11. Khedekar S, Anupriya GR, Patgiri B, Prajapati PK. Chemical characterization of incinerated gold (Swarna Bhasma). Adv Appl Sci Res. 2015;6(12):89-95.

12. Sundarrajan M, Jeelani A, Santhanam V, Durgadevi S, Abirami S. Effect of concentration, ph and time on the morphology of silver nanoparticles synthesized by the green method using Phyllanthus niruri and solanum nigrum leaf extracts. Int J Curr Res. Rev. 2018 Nov; 10:25-9.

13. Jain PK, Lee KS, El-Sayed IH, El-Sayed MA. Calculated absorption and scattering properties of gold nanoparticles of different size, shape, and composition: applications in biological imaging and biomedicine. J Phys Chem B. 2006 Apr 13;110(14):723848 .

14. Beaudet D, Badilescu S, Kuruvinashetti K, Kashani AS, Jaunky D, Ouellette S, Piekny A, Packirisamy M. Comparative study on cellular entry of incinerated ancient gold particles (Swarna Bhasma) and chemically synthesized gold particles. Scientific Rep. 2017 Sep 6;7(1):1-2.

15. Bhaskaran JK, Patel KS, Srikrishna R. Immunomodulatory activity of Swarna Prashana (oral administration of gold as electuary) in the infants-A randomized controlled clinical trial. Int J Res Ay. 2019 Oct 1;40(4):230. 